\title{
Investimento de aspectos
passionais no discurso da
imprensa esportiva
}

\author{
Magnos Cassiano Casagrande \\ Doutor em Comunicação \\ Universidade Federal de Santa Maria \\ Brazil \\ magnoscassiano@yahoo.com.br
}

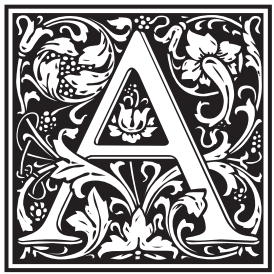

borda-se o futebol como um texto cultural, revelador e configurador de identidades, texto que envolve a cultura, a sociedade, os sujeitos, a comunicação midiática e a indústria do esporte. Olha-se para o futebol através das relações comunicacionais que ele engendra e que nele estão engendradas, algo que conclama pensar os discursos e os valores que o constituem.

Pensar o futebol também consiste em examiná-lo sobre a ótica do jogo, do esporte e da paixão. Sob a ótica do jogo, o futebol é constituinte da cultura, uma atividade voluntária, livre, delimitada no espaço-tempo, que desenvolve sua própria ordem, integra a vida e a amplia, mesmo que atrofiado pela seriedade e pelo excesso de ingerência mercadológica (Huizinga, 2000), ou, uma atividade regulamentada, regrada e competitiva, bem como lúdica, livre e incerta (Caillois, 1990).

Sob a ótica do esporte, desenvolve-se como lazer, entretenimento ou negócio; permite o conhecimento de paixões humanas e sociais a partir da expressão de um contrato de vinculação afetiva e intersubjetiva (Barthes, 2008); apresenta um caráter espetacular e narrativo, marcado por emoção e envolvimento (Volli, 2010); é um meio de comunicação reminiscente que lembra aos homens seus comportamentos e atividades (Gebauer \& Wulf, 2004). No imbricamento entre jogo e esporte, o futebol comunica contratos humanos que

Pour citer cet article, to quote this article, para citar este artigo

Magnos Cassiano Casagrande « Investimento de aspectos passionais no discurso da imprensa esportiva: promoção de intencionalidades e posicionamentos editoriais », Sur le journalisme, About journalism, Sobre jornalismo [En ligne, online], Vol 10, n² - 2021, 15 décembre - december 15 - 15 de dezembro. URL : https://doi.org/10.25200/SLJ.v10.n2.2021.438 
estão no diálogo carregado de tensionamento que se estabelece entre o ambiente cultural do primeiro - o jogo - e o ambiente midiatizado do segundo - o esporte (Campos, 2014).

Já sob a ótica da paixão, o futebol torna-se revelador da conexão psicossocial existente entre esporte, homem e sociedade (Bento, 2013), e assume validade em razão dos afetos que desperta e dos valores que o condicionam. A paixão leva o torcedor a acreditar no jogo, a fazê-lo acontecer e a superar discursos desencantados.

O principal evento futebolístico, a Copa do Mundo, mobiliza a mídia esportiva por um longo período de tempo. As partidas espalham-se por cerca de trinta dias e tem-se uma extensa cobertura da competição. A Copa do Mundo é um evento que eleva a editoria de esportes à condição de protagonismo na maioria dos jornais brasileiros. Em contrapartida, o jornalismo esportivo é tomado como instituidor do esporte, de sua competência técnica, crenças e emoções e responsável pela construção afetiva a ele relacionada (Lovisolo, 2011).

Este processo instituidor ocorre com grande apelo aos afetos, paixões, emoções e sentimentos, os quais são também elementos essenciais do próprio jornalismo. O jornalismo está envolto a uma série de fatores subjetivos e intersubjetivos (Motta, 2003) que permite a revelação de suas intencionalidades. Ademais, narra e discursiva afetos (Mozdzenski, 2018) e tem a emoção como característica intrínseca (Gadret, 2018).

Sobre uma equipe vitoriosa como a Seleção brasileira, os extremos comportados pelo jogo - vitória ou derrota - geram maior interesse dos veículos de comunicação, que se voltam para explicar o sucesso ou o fracasso. Na edição de 2014 da Copa do Mundo (realizada em solo brasileiro), o histórico resultado de Alemanha sete (7) Brasil um (1) possibilitou que as páginas da imprensa esportiva se transformassem em um espaço de exaltação de paixões como frustração, humilhação, vergonha, raiva e melancolia.

Dentre um vasto universo de dispositivos midiáticos que se detém à Copa do Mundo, elege-se as capas de jornais impressos como objeto empírico para o presente estudo. A capa atua como um espaço estratégico, de caráter publicitário, de captação da atenção do leitor, de estímulo à leitura ou compra da publicação e de construção de vínculos sensíveis (Hartmann, Fanfa \& Silveira, 2020); (Casagrande, 2019). A discursivização de acontecimentos que privilegia aspectos passionais enaltece sua característica promocional.

Pressupõe-se que o discurso das capas fala das paixões em meio a uma dinâmica de hibridização entre linguagem jornalística e publicitária. Estampar toda a capa com um único acontecimento/tema representa certo apreço por ele. Assim, a capa torna-se um objeto de paixão do jornalismo, enquanto sua característica monotemática permite propor tal dispositivo como uma metáfora publicitária. Pensando-se o futebol como um produto de alto valor para a imprensa (Costa, 2010) não é demasiado afirmar que ele é enunciado e anunciado nas capas com forte presença do argumento da paixão.

Diante do exposto, elabora-se a seguinte questãoproblema: que marcas discursivas passionais e que posicionamentos editoriais são manifestados na cobertura jornalística da eliminação da Seleção brasileira na Copa do Mundo de Futebol de 2014 e que relações é possível traçar com as eliminações ocorridas na edição anterior (2010) e na edição posterior (2018)? Quanto aos objetivos, propõem-se: a) mapear o investimento temático-figurativo constituinte das capas de jornais impressos; b) propor explicações sobre a relação que se estabelece entre capas, aspectos passionais, intencionalidades e posicionamentos editoriais.

Fala-se em investimento temático-figurativo em referência ao aporte metodológico que baseia a análise realizada no estudo. Recorre-se a preceitos da semiótica discursiva greimasiana (Greimas \& Fontanille, 1993); (Greimas \& Courtés, 2012), utilizando-se de considerações acerca das paixões e do percurso gerativo de sentido. $\mathrm{O}$ percurso gerativo sugere a organização do sentido em três níveis: fundamental, narrativo e discursivo. Reconhecendo a necessária relação entre eles, utiliza-se o último (mais complexo e concreto), o discursivo, que compreende a análise do investimento temático-figurativo.

Analisa-se um conjunto de capas de jornais impressos publicadas em períodos de grande mobilização passional e nacional. A coleta inicial sobre a cobertura das eliminações de 2010, 2014 e 2018 obteve um total de 117 capas. A partir de uma série de recortes, sendo o principal a configuração monotemática da capa, estabeleceu-se um corpus analítico de 45 capas, sendo 13 de 2010, 16 de 2014 e 16 de 2018.

Além desta introdução e das considerações finais este artigo se desenvolve a partir de outras cinco seções: Jornalismo, afetos e linguagem esportiva; Capa: autoimagem do jornal; Articulação metodológica; Sistematização do material empírico e Síntese dos resultados e discussão.

\section{JORNALISMO, AFETOS \\ E LINGUAGEM ESPORTIVA}

As paixões, as emoções e os afetos estão presentes no trabalho jornalístico tanto no seu ser e no seu fazer 
quanto na construção discursiva que se realiza sobre os acontecimentos e nos efeitos de sentido que se pretende comunicar ao público leitor. Acerca de algumas temáticas, como é o caso dos esportes, revelam-se sujeitos, discursos e instâncias imersos num cenário passional e em constante enunciar de aspectos de investimento da subjetividade e das intencionalidades.

Motta (2003) sugere um jogo de intencionalidades e reconhecimentos no jornalismo. Todo ato comunicativo envolve um intercâmbio de experiências, no qual "intervêm inúmeros fatores objetivos, mas principalmente, aqueles fatores subjetivos e intersubjetivos (memórias, emoções, sentimentos, paixões, etc)" (Motta, 2003, p. 8). Ao mostrar-se pretensamente objetivo, o jornalismo não escapa das emoções, dos valores e dos julgamentos. Perceber o jornalismo e suas construções discursivas implica reconhecer sua "interpretação subjetivada ou poética” (Motta, 2003, p. 8).

O que circula pelo âmbito da intencionalidade geralmente encontra-se como um conteúdo implícito, como efeitos de sentido que "derivam tanto dos significados e sinais do texto como de princípios estéticos, morais ou sociais subentendidos no ato comunicativo" (Motta, 2003, p.8). Com base em J. Searle, Motta (2003, p.12) afirma: "a intencionalidade original ou intrínseca do pensamento do sujeito falante se transfere às palavras e frases, que têm por sua vez uma intencionalidade derivada dos pensamentos do sujeito". Além de seu significado linguístico, as palavras carregam impressões de quem enuncia. Elas não são enunciadas sem propósito, especialmente quando remetem a contextos específicos.

Ao enunciar, a instância jornalística condiciona os enunciados, de modo explícito ou implícito, de acordo com suas intencionalidades. Embora seja praticamente impossível discerni-las completamente, o uso de palavras e imagens e os contextos em que estas são empregadas as denunciam. A partir do seu dizer e das materialidades verbais e iconovisuais escolhidas, o jornal revela pistas do que pensa e do modo como se posiciona diante de um acontecimento. Este processo intencional do fazer jornalístico recebe contribuição precisa das paixões, pois, como uma "forma de racionalidade discursiva" (Fiorin, 2007, p. 12), sendo o "móvel da ação", a paixão promove a correlação entre o inteligível e o sensível.

Medina (2008) aponta a primazia que a relação intersubjetiva (a relação entre sujeitos na comunicação) possui para a prática jornalística, além do tensionamento do sujeito, dos objetos e das temáticas. A sensibilidade humana e a subjetividade são constituintes da atividade. Os afetos, implicitamente ou não, estão presentes e são materializados nos e pelos processos jornalísticos.
Mozdzenski (2018) investiga como os afetos são narrativizados e discursivizados pela mídia. A tentativa de compreensão deste fenômeno se dá pelo acionamento da noção retórica de pathos e sua revitalização a partir de uma abordagem sociocognitiva. Nisso, sugere a noção de mundos patêmicos e uma incidência precisa do contexto no processo de comunicação. $\mathrm{O}$ contexto é visto muito menos como condição externa, mas como algo fruto das representações construídas pelos sujeitos das situações vividas, acionadas em toda relação intersubjetiva. Os mundos patêmicos seriam constituídos a partir de um dinâmico processo que envolve representações afetivo-cognitivas mobilizadas com a finalidade de sensibilizar o destinatário.

No ato discursivo ocorre um acionamento estratégico de elementos de diversos tipos de acordo com a finalidade afetiva que se pretende. Enquanto isso, o destinatário interpreta as atitudes de quem enuncia a partir de modelos afetivos pré-construídos sobre o que é positivo ou negativo, agradável ou desagradável. Tais modelos condicionam sua opinião sobre a postura comunicativa do enunciador. Em resumo, o pathos visado resulta do agenciamento entre modelos afetivo-cognitivos já existentes (pathos pré-discursivo) e a intencionalidade de gerar estados emotivos a partir do discurso (pathos discursivo), considerando-se os contextos e mundos patêmicos acionados em cada situação de comunicação (Mozdzenski, 2018).

Gadret (2018) estuda a emoção e sua relação com o enquadramento de fatos, acontecimentos e temáticas pelo jornalismo. A emoção se apresenta como fundamental para o entendimento das relações empreendidas entre sujeitos, objetos e natureza. O jornalismo é um dos espaços de circulação das emoções. Nele, as emoções aparecem "ancoradas em temas universais, reificando, reelaborando e construindo discursivamente crenças sociais supostamente compartilhadas, baseadas em avaliações morais que devem ser aceitas pelo público para que este adira ao contrato de comunicação proposto" (Gadret, 2018, p. 292-293). Sendo parte da tomada de decisões dos sujeitos, ela perpassa e age na intepretação e avaliação dos acontecimentos pelo jornalismo, no processamento e na construção discursiva das informações.

O enquadramento jornalístico é organizado a partir de uma avaliação moral articulada pela emoção (Gadret, 2018). Esta avaliação, oriunda de crenças sociais e do contexto sociocultural e que implica em decidir o caráter valorativo das situações (boas ou más, positivas ou negativas, amáveis ou odiosas), permite ao jornalismo instaurar uma problemática ou um conflito, propor recomendações e assumir um posicionamento.

De posse deste julgamento, por tê-lo elaborado, o jornalismo constrói e apresenta diferentes emoções 
"como um efeito de sentido que suporta, justifica e interpreta essa avaliação" e, assim, propõe o enquadramento de um fato, acontecimento ou temática (Gadret, 2018, p. 309). A emoção é tomada como um caminho que articula ou aciona uma avaliação moral a partir de uma estrutura narrativa manifestada por materialidades discursivas. Estas materialidades, como palavras e imagens, "convidam os sujeitos a sentir determinadas emoções por meio de um reconhecimento daquela estrutura narrativa" (Gadret, 2018, p. 309). Os sujeitos dos quais se fala são postos a convidar o destinatário para compartilhar o julgamento sobre eles realizado pela instância jornalística. Em razão disso, por exemplo, somos convidados a compartilhar as alegrias e tristezas dos esportistas. Porém, constantemente essa avaliação moral binária, recorrente no âmbito do jornalismo esportivo, não supera o nível da superficialidade e acaba por simplificar aspectos e relações sociais extremamente complexas.

No âmbito da imprensa esportiva, ao analisar a recepção das derrotas da Seleção brasileira de futebol em Copas do Mundo, Costa (2010) aponta que as emoções se tornaram aspecto constituinte do texto jornalístico esportivo. Explorar o caráter afetivo e passional do futebol consiste em estratégia discursiva e narrativa voltada ao interesse comercial de impactar o leitor e consumidor.

Pela via dos afetos e sentimentos dos torcedores e sua representação, pensa-se a emoção como um elemento que interfere no fazer discursivo jornalístico: "Quando o assunto é futebol - e principalmente envolve a seleção brasileira - a imprensa costuma ficar longe da imparcialidade e objetividade, ideais pelos quais, muitas vezes, afirma se pautar" (Costa, 2010, p. 93). O excesso, a polêmica, o drama, o tom superlativo, as clássicas dicotomias como heroísmo e vilania, alegria e tristeza, elementos característicos do melodrama e do folhetim, são constantes nas páginas da imprensa esportiva.

O jornalismo esportivo estabelece de modo instantâneo suas conclusões e julgamentos e, por vezes, parece desconhecer a real potencialidade dos afetos, entre elas a criação de vínculos. Ali, os vínculos são superficiais e passageiros, se esgotam tal como cada edição diária. Porém, ressalta Costa (2010), este tipo de produção pode estar alinhada e corresponder às expectativas dos destinatários.

Para Lovisolo (2011), o jornalismo esportivo atua como formador e difusor de competências técnicas, crenças e emoções. Sugere-se um papel central da mídia e do jornalismo esportivo na construção afetiva relacionada ao esporte e na constituição do próprio esporte moderno. Ambos "realizaram a tarefa de construir as emoções as sensibilidades, as formas de recepção e os marcos interpretativos, enfim, fizeram um público informado, apreciador e crítico do esporte" (Lovisolo, 2011, p. 91). Para além do conhecimento técnico, o jornalismo esportivo desenvolve e divulga uma linguagem que se propõe a criar suas próprias emoções e a emocionar.

Todavia, ao se construir uma base emocional receptiva não se escapa à seletividade. Classificações dicotômicas não são capazes de revelar as diversas facetas de um tema ou assunto (Fortes, 2015). Temas e expressões atinentes a uma construção muito mais emotiva - quando esta é apresentada como um efeito visado no âmbito do discurso do que crítica, são capazes de dificultar o acesso a assuntos caros ao esporte e ao futebol que recebem espaço limitado nas páginas esportivas, a exemplo das questões de gênero, raça, classe social, corrupção e violência. A costumaz linguagem de guerra, de enfrentamento, de rivalidade $\mathrm{e}$ vitória a qualquer custo parece dificultar o desenvolvimento da empatia por um debate aprofundando sobre aqueles assuntos.

\section{CAPA: AUTOIMAGEM DO JORNAL}

Entende-se a capa de jornal como um dispositivo composto de materialidades verbais e iconovisuais que promove, dá visibilidade e apresenta ao leitor um conjunto de informações, intencionalidades e posicionamentos editoriais. A capa é a página mais importante, o espaço gráfico que mais recebe atenção e que proporciona uma síntese da edição diária de um jornal. Sua constituição se dá a partir de uma hibridização entre a esfera jornalística e a esfera promocional.

A capa manifesta a partir de seus elementos, a dizer: a) elementos fixos, de identificação do jornal: nome, logotipo, dados espaço-temporais, presentes em todas edições; b) elementos variáveis/móveis: manchetes, fotografias, ilustrações, chamadas de texto, anúncios (Carvalho, 2012), indícios do que configura sua identidade editorial. Outrossim, a capa se insere em dispositivos mais amplos como o jornal impresso, o jornalístico, o midiático, o mercadológico e o cultural, que também condicionam o que ela significa.

A manchete é o ponto central de atração de uma capa de jornal. Possivelmente, o primeiro elemento a tocar o lado sensível do leitor e aquele que mais vira notícia em outros meios de comunicação. Por vezes, é o único texto a ser lido pelo leitor. Como um todo, as manchetes "funcionam como focalizadores, à medida que ativam ou selecionam áreas do conhecimento de mundo que temos arquivadas na memória" (Aguiar, 2012, p.141). Assim como o slogan de um anúncio publicitário, é breve e sucinta para facilitar a leitura e seu processamento. 
O vínculo entre manchete e fotografias ou ilustrações constroem um sentido geral para a principal informação presente na capa do jornal (Valdetarro, 2003). A autora lembra que as montagens fotográficas, bem como as ilustrações, os gráficos e as charges, representam uma ação editorial do jornal sobre a informação, em que se pode imprimir uma crítica, uma opinião, uma sátira.

A escolha do conteúdo da capa orienta-se por critérios de noticiabilidade jornalística já consolidados. Porém, pode seguir escolhas particulares de cada veículo e depender da prioridade e do interesse em comunicar determinado conteúdo (Buonanno, 2015). A capa transforma-se em um ponto de referência, visibilidade e valorização dos acontecimentos e dos jornalistas. Trata-se de uma materialidade simbólica que é capaz de revelar e definir a identidade do jornalismo.

Além de informar, representar/encenar, entreter e persuadir a capa atende a alguns papeis específicos (Ryan; Conover, 2004) como: identificação do jornal; produção de interesse; organização e síntese; definição do impacto visual; servir como anúncio da publicação. Conforme Casagrande (2019, p. 83), "através da capa o veículo enuncia e se autoanuncia, isto é, a capa é a autoimagem do jornal [...], ou, ainda, um sistema autorreferencial que permite mostrar e dar visibilidade a seus interesses e valores, bem como às temáticas enfatizadas e as imagens de si que se deseja veicular”. Através de materialidades verbais e iconovisuais desenvolve-se um texto que permite à instância jornalística enunciar características destacáveis de um fato e anunciar intenções de representação.

É compreensível o posicionamento editorial de um veículo de comunicação como o jornal estar estampado na principal página de uma publicação, visível tanto no formato impresso quando no formato digital. Hartmann; Fanfa; Silveira (2020), ao investigarem o tensionamento das capas e sua (re)configuração numa era de jornalismo de plataformas, enfatizam sua importância para o veículo, sua atratividade e seu caráter transmidiático.

Além da internet e redes sociais, as capas circulam por meios de comunicação tradicionais (Casagrande, 2019). Programas informativos televisivos, portais online de notícias e o rádio as utilizam como síntese do que é destaque no noticiário, especialmente através da leitura de manchetes ou apresentação de imagens. No âmbito futebolístico, frequentemente as capas aparecem em programas de debate esportivo.

Jornais seguem investindo nas capas pois percebem nelas "um recurso singular de promocionalidade dos veículos, de reconhecimento de sua identidade editorial e de expressão de sua posição ideológica" (Hartmann, Fanfa \& Silveira, 2020, p. 108). Ocorre um movimento de (auto)promoção (Castro, 2012) com a intenção de publicizar e projetar a capa. Enquanto projetar é divulgar, propagar e fazer conhecer, projetar remete a conferir respeito e credibilidade ao produto/ marca/serviço jornalístico.

Ao menos dois contratos de comunicação (Charaudeau, 2006) se intercalam na capa de jornal: o informacional, em que prevalece a visada da informação, e o promocional, em que prevalece a visada da captação. Ao agenciar as duas visadas, a capa desenvolve um jogo entre fazer-saber e fazer sentir. Ela desenvolve um tom informacional quando procurar descrever, narrar ou explicar os acontecimentos e, ao mesmo tempo, como está inserida em um ambiente mercadológico, precisa conter elementos capazes de captar a atenção e o interesse dos leitores. Eis que, apela-se aos dramas, aos afetos, às emoções e às paixões, que incidem tanto sobre os discursos quanto sobre os enunciadores.

Mesmo atrelada a várias características do cânone jornalístico tradicional - como hierarquização dos fatos e valores-notícia - a capa avança sobre eles, instituindo-se como um dispositivo com características promocionais. As capas são pensadas como estruturas alegóricas: "Convenciona-se que as capas presentam e representam o veículo jornalístico: presentam-no ao constituírem-se como plena materialidade de sua postura editorial; representam-no ao instituírem-se com voz própria" (Hartmann, Fanfa \& Silveira, 2020, p. 108). Para o jornal impresso, sua principal página configura-se num dos seus fundamentais modos de se (a)mostrar, mesclando aspectos de ordem promocional e editorial. Em sua superfície discursiva figurativiza interesses, desejos, intencionalidades, crenças e representações acerca de acontecimentos e temáticas.

\section{ArTiCUlaÇÃo metodológiCA}

A semiótica se interessa pelas paixões ao perceber nelas a importância que possuem na geração da significação discursiva. Antes preocupada apenas com o estado das coisas, a semiótica volta-se para os estados de alma (Greimas \& Fontanille, 1993) com a intenção de ampliar a compreensão da constituição do enunciado e da própria enunciação. A presença de elementos patêmicos nas atividades humanas, o reconhecimento das paixões como aquilo que impulsiona a ação e o fato da enunciação atrelar-se a uma discursivização da subjetividade levam a semiótica a sinalizar a presença constante das paixões nos textos (Greimas \& Fontanille, 1993). As paixões são entendidas como efeitos de sentido que se constituem no discurso e a partir dele. 
No âmbito semiótico, os efeitos de sentido surgem a partir das relações entre sujeito, objeto e texto expressas em proposições. Desse modo, não dizem respeito apenas aquele que enuncia, mas a todos os sujeitos que, com suas experiências e vivências, valores, desejos e interesses, se envolvem no agenciamento discursivo.

Para a semiótica greimasiana, o sentido é gestado sob a forma de um percurso gerativo composto por três níveis (Greimas \& Courtés, 2012): - fundamental: onde surge uma oposição semântica de base; - narrativo: em que a narrativa é organizada a partir do ponto de vista dos sujeitos; e discursivo: em que a narrativa e os elementos de base são assumidos pelo sujeito da enunciação. É o nível discursivo que oferece as categorias analíticas utilizadas nesta pesquisa: os investimentos de tematização ou figurativização. Aqui, investimento se vincula à exposição de intencionalidades, ao ato de carregar de afeto pessoas, ideias ou objetos.

A tematização é um investimento semântico que se refere a um conjunto de traços, ideias, valores, pensamentos e argumentos num plano abstrato. Greimas \& Courtés (2012) a apresentam como um procedimento que dissemina valores já em junção com os sujeitos a partir de temas, instaurando a possibilidade de uma figurativização. Os temas correspondem a um conjunto de ideias referentes a modos de ser, fazer, crer, sentir e pensar dos sujeitos, objetos ou funções. Ao desenvolver um tema, o enunciador organiza o discurso como uma trama de argumentos que se imbricam para a apresentação de valores de conduta, pensamentos e sentimentos (Peruzzolo, 2015). Trata-se de um processo que atende à intencionalidade do enunciador em fazer o destinatário acreditar nos valores que sustentam o discurso proposto.

A figurativização é um investimento que procura dar concretude, proximidade com o real e produzir uma correspondência das ideias e valores com o mundo natural. Esta invasão do concreto no discurso exige uma "competência para enunciar figurativamente [...] um saber-contar ou saber-representar [...] ainda é necessário um mínimo de imaginação" (Greimas \& Fontanille, 1993, p.278). Substantivos concretos, verbos (especialmente de ação), adjetivos relacionados a qualidades físicas e profissionais, metáforas e outras figuras de linguagem, fotografias, marcas temporais, espaciais e actoriais, acontecimentos, fatos históricos, traços de sentimento e afeto, são alguns exemplos de figuras.

O investimento figurativo é responsável pela concretização gradual de determinado tema e por um acréscimo de qualidade. Para Barros (2004, p. 13), "as figuras concretizam sensorialmente os temas e dão a eles corporalidade”, ou seja, os temas recebem um investimento constituído por "traços sensoriais de cor, de forma, de cheiro, de sons etc". Trata-se de um processo de fazer-crer idealizado por um enunciador, que orienta o juízo que o destinatário deve fazer sobre as figuras e à temática que elas remetem, atuando de modo decisivo no processo de persuasão.

\section{SiSTEMATIZAÇÃo DO MATERIAL EMPÍRICO}

Coletou-se capas de jornais impressos referentes a cobertura da eliminação da Seleção brasileira diante da Seleção alemã na semifinal da Copa do Mundo de Futebol de 2014, partida realizada em o8 de junho do mesmo ano. Com o objetivo de traçar um paralelo no âmbito da utilização de elementos discursivos passionais e fazer a pesquisa desenvolver-se de modo comparativo, coletou-se capas da cobertura das eliminações ocorridas na edição anterior (derrota para a Holanda pelo placar de 2 a 1 nas quartas-de-final da Copa do Mundo de 2010) e na edição posterior (derrota para a Seleção da Bélgica pelo placar de 2 a 1 nas quartasde-final da Copa do Mundo de 2018). Inicialmente, tratou-se de uma coleta aleatória, buscando-se o maior número possível de capas dos mais variados jornais brasileiros.

O Quadro 1 mostra as fontes da coleta, o número de capas coletadas e quantidade que forma o corpus analítico. Já o Quadro 2 apresenta os jornais que tiveram capas analisadas em cada uma das eliminações (2010, 2014 e 2018).

Quadro 1: Fontes, coleta e corpus

\begin{tabular}{|llll|}
\hline Fontes da coleta & Ano & $\begin{array}{l}\text { Coleta } \\
\text { inicial }\end{array}$ & Corpus \\
\hline $\begin{array}{l}\text { Fac símiles de jornais; } \\
\text { Sites: Brainstorm 9, }\end{array}$ & 2010 & 19 & 13 \\
$\begin{array}{l}\text { Imgur.com, Sevirade- } \\
\text { sign.com e Vermino- } \\
\text { sosporfutebol.com }\end{array}$ & 2014 & 55 & 16 \\
& 2018 & 43 & 16 \\
\cline { 2 - 4 } & Total & 117 & 45 \\
\hline
\end{tabular}

Fonte: elaborado pelo autor

Quadro 2: Capas de jornais analisadas

\begin{tabular}{|c|c|}
\hline Ano & Capas de jornais \\
\hline 2010 & $\begin{array}{l}\text { Diário do Pará (PA), Super Notícia (MG), O } \\
\text { Tempo (MG), Corrreio* (BA), Agora (SP), } \\
\text { Diário de São Paulo (SP), Diário de Canoas } \\
\text { (RS), Diário de Pernambuco (PE), Pioneiro } \\
\text { (RS), O Povo (CE), Jornal de Santa Catarina } \\
\text { (SC), Correio Braziliense (DF), Folha de São } \\
\text { Paulo (SP). }\end{array}$ \\
\hline
\end{tabular}




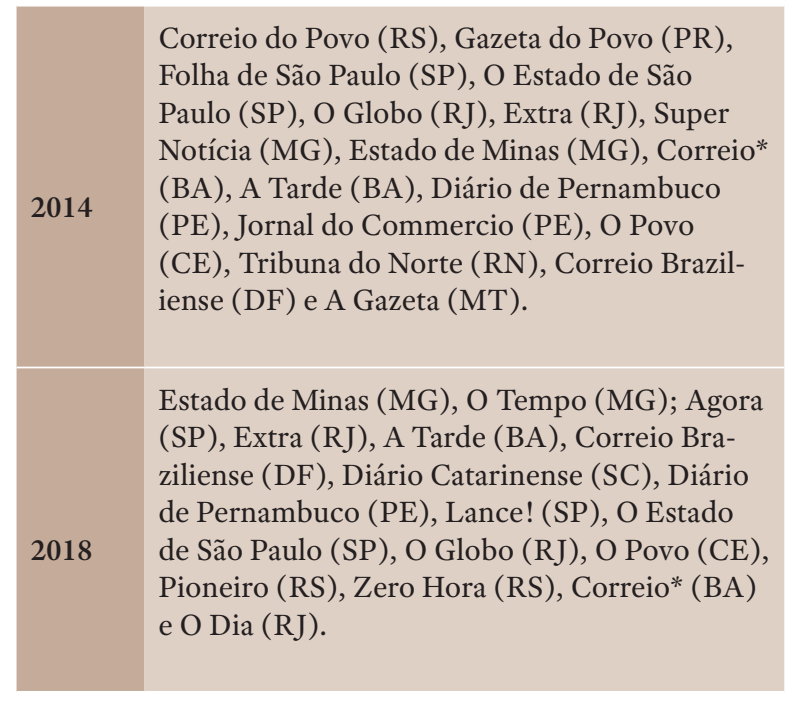

Fonte: elaborado pelo autor

As capas escolhidas para análise possuem em comum o fato de serem, majoritariamente, monotemáticas, ou seja, sua constituição se dá a partir de um único acontecimento, sendo este o critério norteador para constituição do corpus. Como estratégia metodológica, opta-se por privilegiar a identificação de elementos discursivos acionados por um número expressivo de instâncias jornalísticas. Nome ou tipo de veículo não interferiram na escolha das capas, pois, entende-se que o contato com exemplares de distintas localidades e organizações permite averiguar de um modo mais amplo as manifestações do jornalismo esportivo e seus modos de pensar, fazer e sentir quando este assume a condição de protagonismo.

A análise mais detalhada de 2014 atende a justificativa de que esta instaurou um desafio diferenciado para o jornalismo esportivo nacional. Feito isso, expande-se o estudo comparando os resultados encontrados com elementos discursivos presentes nas capas de 2010 e de 2018.

\section{SÍNTESE DOS RESULTADOS E DISCUSSÃO}

A análise das capas publicadas após a eliminação da Seleção brasileira na Copa do Mundo de 2014 permite apontar a prevalência de aspectos passionais como frustração, vergonha e tristeza. Os discursos construídos se originam no caráter vexatório e humilhante (para o lado brasileiro) do resultado da partida entre Brasil e Alemanha e na suposta incorporação do sofrimento pelas instâncias jornalísticas. Em torno desse percurso temático se desenvolve grande variedade de marcas passionais, entre elas: consternação, luto, trauma, fraqueza, ilusão, desilusão, nostalgia, ressentimento, raiva, indignação, constrangimento, desolação, redenção, desiquilíbrio, desesperança e melancolia. Todas aparecem como adereços dramatizantes baseados em um estereótipo cultural pertencente ao senso comum do futebol que permite tratar um resultado elástico - com grande diferença de gols - de tal maneira.

Figura 1 - Exemplos de capas analisadas Copa 2014 (jornais O Povo, Estado de Minas e O Globo).
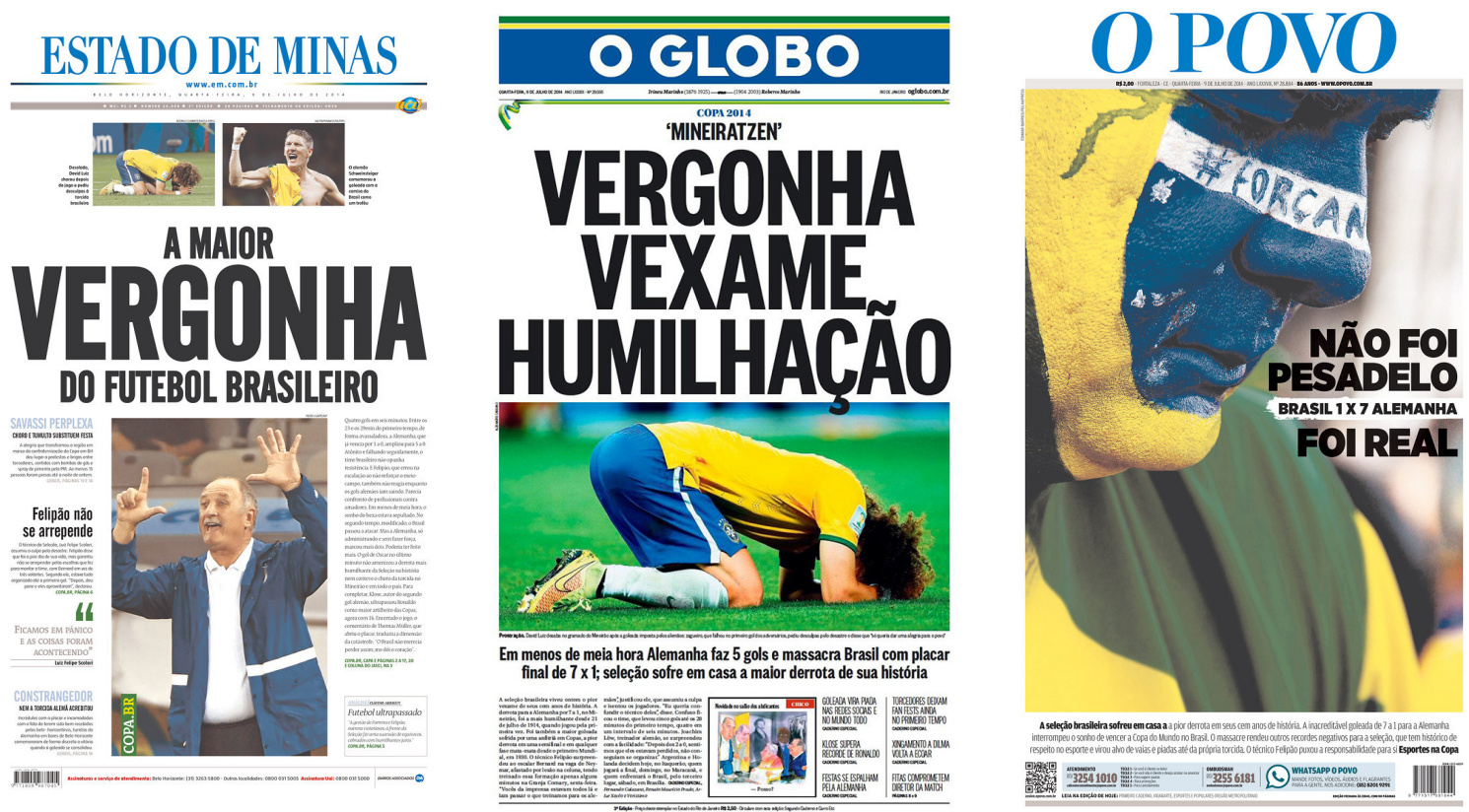

Fonte: Conforme Quadro 1. 
A exploração editorial do resultado de 7 a 1 configura-o como uma vergonha nacional. O sujeito Seleção e, especialmente, o comandante da equipe, são apontados como os responsáveis por causar tal sentimento diante de seus adeptos. Desconsidera-se qualquer valor positivo do sujeito em detrimento de um tratamento pejorativo. A partir de um instinto autorizativo, os enunciadores assumem a condição de apresentar a performance como indesejada.

A não conjunção com o objeto de valor é utilizada como licença para a tessitura de críticas, especialmente ao técnico Luiz Felipe Scolari. Este, de um sujeito paternal e campeão, é transformado em figura do fracasso. A frustração encontra seu mal causador. Os enunciadores constroem uma imagem negativa a partir de um discurso dotado de antipatia e aversão. Manifesta-se um efeito reverso: a potencialização dada quando da exaltação é semelhante quando do resultado negativo, apenas dedicada ao viés contrário.

A fotografia da bola em contato com as redes brasileiras e o goleiro deitado ao chão, fato ocorrido sete vezes ao longo da partida, é apenas um dos exemplos de uma materialidade discursiva composta por uma carga afetiva que engendra determinados significados. Ela expõe um sofrimento, apresenta-se como um ícone da derrota. Tal momento capturado pelas lentes tornase um dos elementos que concentra a tristeza, assim como imagens dos jogadores ao chão e dos torcedores chorando. A fotografia marca o enquadramento e o recorte da cena capturada.

Enquanto que no teatro o espectador é um observador, no esporte ele é um ator; este é um dos fatores que leva o indivíduo a amar o esporte, revelando e manifestando a partir dele paixões/emoções variadas. Além de uma vinculação afetiva, a ação dos espectadores do esporte constitui uma forma de comunicação (Barthes, 2008). Os torcedores e seus gestos são representados em vitórias ou nas derrotas, em momentos de tristeza ou alegria, de exaltação ou decepção. A torcida presente nas arenas esportivas transforma-se em um "agente de geração de imagens, principalmente de vinculação" (Campos, 2014, p. 209) entre aqueles que acompanham a prática in loco e aqueles que acompanham pelos meios de comunicação.

Diante disso, constata-se que a imagem de choro aparece com grande frequência nas capas. O choro é uma reação fisiológica - um sofrimento do corpo uma manifestação corporal (Greimas \& Fontanille, 1993). Seu efeito é potencializado quando desmancha a pintura de cores da bandeira nacional presente nos rostos dos torcedores. Procura-se plasmar um efeito de comoção nacional pela representatividade e valor simbólico que possui um rosto pintado. Trata-se de uma operação em que se procura representar a emoção do todo, inclusive do enunciador, pela particularidade de um rosto em que o sonho do hexa se desmancha junto com a pintura.

A apresentação de personagens em grande plano atua como elemento figurativo que amplia a dramaticidade do conteúdo abordado. Em capas que adotaram tal estratégia ocorre a tentativa de representação de valores abstratos a partir de uma figura humana em destaque. Figuras hiperbólicas, marcas temporais e dados estatísticos e históricos são utilizadas para recobrir a magnitude e o caráter histórico de um placar. Marcas espaciais, como a denominação do estádio, criam um sentimento de pesar para o local da partida. Já a metonímia do todo pela parte é utilizada para representar um suposto sentimento nacional a partir da representação de um único personagem.

As análises constatam que a cobertura em 2014 se encontra pautada pela presença de um percurso disfórico. O desejo de conjunção com a vitória não é alcançado e o querer-ser bem como o crer-ser transformam-se em não-poder-ser. A descontinuidade da esperança de ida para a final revela uma imprensa frustrada, que mostra uma face raivosa. Em situações isoladas, trabalha-se a nostalgia, a sátira e a redenção.

Nota-se que ocorre a promoção de posicionamentos editoriais como a mudança de julgamento em torno do favoritismo da Seleção brasileira e em relação a algumas personalidades, exploração da tristeza de torcedores e jogadores, simulacro de incorporação de sofrimento, veneração do desempenho da Seleção alemã e sua superioridade, reverberação da ideia de complexo de vira-latas, efeito de impessoalidade e abandono. Os julgamentos e as qualificações denunciam a proximidade, a atividade e o estado passional dos enunciadores.

Estabelecem-se supostos vínculos de emotividade e pertencimento e evoca-se certa retórica patêmica para moldar as relações entre os interlocutores em questão. Recorre-se ao ufanismo, ao orgulho nacional e ao patriotismo. Tal posicionamento é abandonado com a ocorrência do 7 a 1 . Assume-se uma nova máscara, de posicionamento contrário a um futebol tido como atrasado e ultrapassado.

Em comparação à cobertura das eliminações em 2010 e 2018, inicia-se com aquilo que se denomina figura do adiamento. Trata-se de uma referência ao desejo de conquista do sexto título mundial e sua constante postergação a partir de sucessivos insucessos após a conquista do quinto, em 2002. Encontra-se expressões como "Chega logo, 2014", "Fica para 2014" e "Faltam 1471 dias para o Hexa" em capas de 2010 e, "Fica para 2022", "O sonho adiado!", "O Hexa não vem”, "Hexa adiado", "Continua batendo na trave o nosso sonho 
Figura 2 - Exemplos de capas analisadas Copa 2010 (jornais O Tempo, Diário de Pernambuco e Diário do Pará).
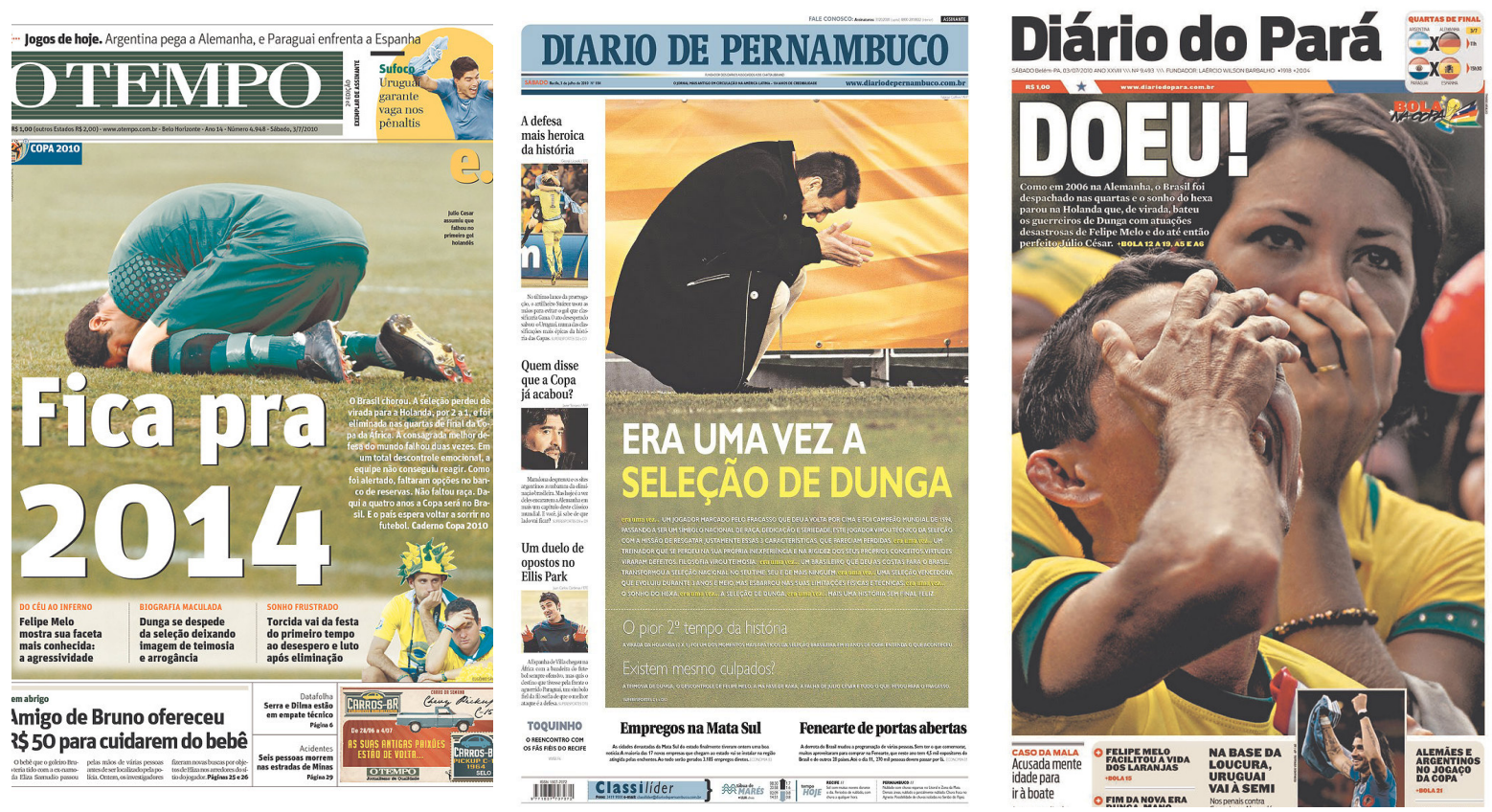

Fonte: Conforme Quadro 1.

pelo hexa", "Hexa? Só se Catar em 2022", "Um Hexa engasgado" e "Hexadesolação" em 2018.

As expressões, ao mesmo tempo que datam o adiamento, passam a confeccionar o Sonho do Hexa em ansiedade, em trauma, em pesadelo. Verifica-se a existência de uma tessitura que é acionada, se repete e é retroalimentada ao longo das três edições. $\mathrm{O}$ mantra do favoritismo criado em cada início de competição favorece a manifestação da dicotomia ilusão/desilusão nas capas.

Constata-se a presença de uma economia da lembrança e do esquecimento. A cobertura de 2010 sugere esquecer imediatamente a eliminação, reformular o futebol e pensar em 2014. Em 2014, pauta-se pela tentativa de apagamento do Maracanazo ${ }^{1}$, ocorrida às avessas, não através de um grande feito, mas de uma derrota que o supera. Já em 2018, joga-se com a dicotomia ilusão/desilusão.

Outra figura com presença constante nas capas de 2010 e 2018 é a do choro, assim como em 2014. Além do choro, as imagens plasmam reações de desolação, desespero, tristeza ou vergonha, em que torcedores e jogadores aparecem com o rosto encoberto seja pelas mãos ou elementos como camisas, chapéus ou bandeiras. Quanto aos jogadores, aparecem ao solo, agachados, ajoelhados ou deitados, em estado de lamentação, ou, ainda, em pé, porém, cabisbaixos.

Utilizar plano de fundo na cor preta em toda capa ou em partes dela, em referência ao luto, foi estratégia adotada por algumas instâncias jornalística em 2014 . Verifica-se que o mesmo não ocorre com as capas de 2010 nem com as capas de 2018. Considera-se que tal resultado remete a uma relativização do impacto passional da derrota nestas edições, enquanto que naquela aparece como forma de enfatizá-lo.

No âmbito das qualificações, enquanto em 2014 predominam termos como vexame, vergonha, fiasco e humilhação, em 2010 as manchetes guiam-se por dor, decepção e teimosia e, em 2018, adeus, lamento, queda, sofrimento, falhas, desolação e honradez. Tanto em 2010 quanto em 2018 são termos menos ásperos e ofensivos.

Destaca-se, também, o tratamento discursivo dado aos comandantes da equipe: Dunga em 2010, Luiz Felipe Scolari (Felipão) em 2014 e Tite em 2018. Em 2010 e 2014 elege-se o técnico como vilão e um dos responsáveis diretos pela eliminação da equipe. Sobre Dunga, expressa-se o desejo de sua demissão. Sobre Felipão, imagens do treinador nas adjacências de qualificações verbais como humilhação, vexame, vergonha e fiasco, denunciam o posicionamento dos enunciadores sobre o técnico. Já sobre Tite, a carga valorativa apresenta mais positividade, desliza-se entre a frustração, a dor, o orgulho e um desejo de continuidade e reconfiguração do trabalho.

O aspecto da frustração pela derrota, mais evidente em 2014, assume determinadas performances e sobre ele cria-se o efeito de ser coletiva. Faz-se prevalecer dois 
Figura 3 - Exemplos de capas analisadas Copa 2018 (jornais A Tarde, Correio Braziliense e Lance).
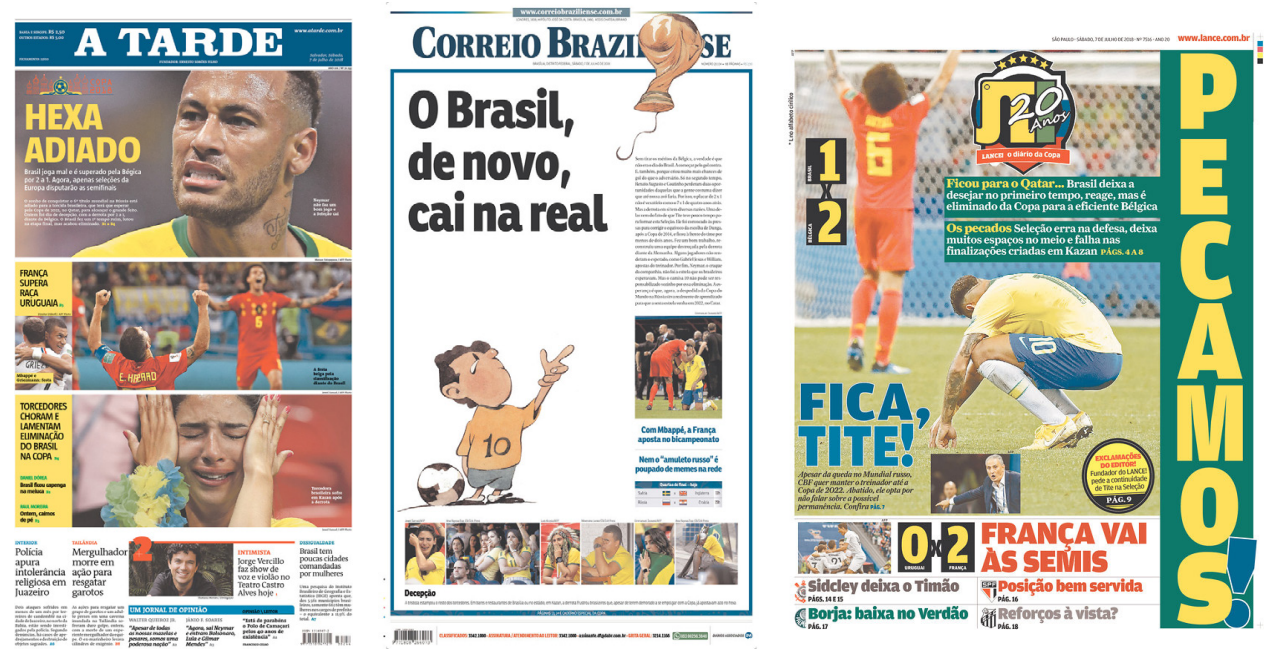

Fonte: Conforme Quadro 1.

rituais estratégicos de emocionalidade (Whal-Jorgensen, 2013): descrições das emoções do outro, seja grupo ou indivíduo e a confrontação entre normalidade e inesperado. Desenvolve-se um continuum de frustração, iniciado em 2006, que se seguiu por 2010, 2014 e 2018. Porém, essa frustração é também do fazer jornalístico. Julga-se que um fazer-sentir sobrepõe-se a um fazer-saber. Os afetos, as paixões e as emoções entrelaçam-se ao processo de construção do texto (Gadret, 2018) e fundamentam os efeitos de sentido visados (Mozdzenski, 2018).

Identifica-se um pulsar de esquecimento e de lembrança quanto aos acontecimentos. Ademais, mascaram-se deficiências através da dramatização e da euforia e disforia seletivas. O discurso de raiva, aversão e contrariedade direciona-se às personalidades ligados ao jogo jogado - dentro das quatro linhas -, não àquelas que atuam em seus bastidores. $\mathrm{O}$ emocionalismo e a dramatização em torno do 7 a 1, por exemplo, prejudicam (intencionalmente ou não) o acesso a uma análise mais aprofundada das estruturas que o resultado mostrou estarem amplamente danificadas.

Os resultados mostram uma necessidade urgente do jornalismo na busca por respostas e culpados para os acontecimentos. Como consequência, peca-se na criatividade e não se consegue produzir um espaço de defesa e de escape legítimo para sua atuação. A construção a partir do instantâneo leva à mudança instantânea de posicionamento, que é apresentada de maneira natural. O processo interpretativo pautado apenas pelo resultado de uma partida representa uma instabilidade proposital. As fórmulas para a vitória ou julgadas adequadas para alcançá-la são negligenciadas com a ocorrência do resultado negativo.

O discurso das capas, claramente, apresenta uma orientação persuasiva calcada em apelos ao sensível.

A exploração de dicotomias como apoiar e desemparar, aproximar e afastar, e as mudanças repentinas de posicionamento, ao mesmo tempo que interferem no modo de pensar e sentir do leitor, confundem-no. Porém, sabe-se que a exploração de paixões de alegria e paixões de tristeza são elementos formadores e mantenedores do encanto da audiência com o futebol. Afinal, está-se a falar de um produto que é muito caro aos meios de comunicação, especialmente no âmbito mercadológico.

\section{CONSIDERAÇõES FINAIS}

Temas e figuras são determinações sócio-históricas e ideológicas que possuem a função de revestir transformações de estado, relações entre sujeitos e objetos de valor e relações de conjunção e disjunção. Aqui, o investimento temático-figurativo está associado a marcas de ordem passional que atuam na publicização de posicionamentos editoriais que, manifestos numa capa de jornal, divulgam as intencionalidades de determinada instância jornalística e ajudam a trilhar possíveis caminhos de interpretação acerca de um acontecimento. A investigação das capas apontou certa pluralidade de posicionamentos e marcas discursivas, os quais revelam o modo de pensar das instâncias jornalísticas frente a determinados acontecimentos e frente ao desafio de cobrir o principal evento esportivo mundial.

Os efeitos de sentido da capa são dados através da interação entre materialidades verbais e iconovisuais, contextos e sujeitos. Como metáfora, a capa se situa entre uma representação dos fatos e o leitor. Temse uma construção elaborada intencionalmente que envolve o leitor (Motta, 2003), o qual pode recusar, negar seu sentido ou acusar certa inexistência de sen- 
tido, menos recusar seu envolvimento com a metáfora, que prima pelos aspectos afetivos. A exploração de tais aspectos torna-se uma via reveladora do modo como o jornalismo aborda os acontecimentos futebolísticos. $\mathrm{O}$ estudo mostra que o investimento temático-figurativo procura dar vida e concretude à carga subjetiva que comporta as intencionalidades de um discurso, tornando-a analisável e mensurável.

Constata-se um subaproveitamento e um enfraquecimento do potencial da capa e do potencial da sua linguagem, especialmente pela semelhança na escolha das imagens, na redação das manchetes, nas qualificações utilizadas entre diversos jornais. As capas analisadas investem temática e figurativamente de modo distinto entre uma Copa do Mundo e outra (apesar de algumas características se repetirem), porém, investem de modo muito semelhante quando se referem ao mesmo acontecimento. Esboça-se um limite da capa como diferenciador ideológico e mercadológico dos veículos, geralmente imposto pela própria instância jornalística.

Considerando-se as paixões como marcas de uma suposta subjetividade, inclusive nos discursos, julga-se que elas fazem falar mais facilmente os posicionamentos editoriais assumidos pelas instâncias jornalísticas. Quanto mais os discursos se pautam pela presença de marcas discursivas passionais mais propensos estão a revelar suas intencionalidades. Um dos pontos que permitiu a identificação dos posicionamentos assumidos pelas instâncias jornalísticas é justamente o fato delas se aproveitarem do cenário passional que permeia a competição e agregarem a seus discursos marcas que, supostamente, representam o que se sente antes e após um acontecimento. Ao fazer falar as decisões das instâncias jornalísticas, as capas atuam como materialidades que registram o modo de atuação destas na cobertura de um acontecimento e transformam-se em imagens formadas acerca de uma Copa do Mundo.

Em meio a este contexto, depara-se com aquilo que Sodré (2006) chama de emocionalismo midiático: uma espécie de fazer sentir, na tentativa de fazer prevalecer, no caso do jornal impresso, determinados posicionamentos editoriais. Além de moldar os discursos midiáticos, o fazer sentir reverbera nos discursos sociais como um todo, influenciando a formação da opinião pública. Uma construção de imagens convertidas no próprio real, às quais, segundo o autor, as audiências engajam-se pelo viés da afetividade. Nesse processo, os discursos ajudam a manter a relação entre mercado e consumidor. Trabalhar aspectos passionais/ afetivos constitui importante ferramenta para fazer o público desejar e consumir um produto, uma marca ou um serviço. Porém, como o próprio Sodré argumenta, é mais do que tempo de reconhecer que as relações de comunicação se emancipam a partir dos afetos, da corporeidade, da conexão entre corpo e espírito.

A partir dos preceitos da semiótica discursiva e da semiótica das paixões, é possível dizer que a prática jornalística e o discurso jornalístico não são construídos ou formulados sem que haja um conjunto de intenções que guiam seu fazer, seja influenciar, seja distorcer, seja fazer prevalecer um ponto de vista ou apresentá-lo, seja desenvolver estratagemas para evidenciar ou dispor nas entrelinhas seus posicionamentos. Pretensamente imparcial ou não, o texto jornalístico intenciona uma sanção positiva por parte do seu destinatário. Os posicionamentos editoriais derivam então de uma passionalidade, um vínculo emocionalafetivo atrelado a uma intencionalidade. Ao mesmo tempo, pela via das marcas discursivas de aspecto passional denunciam-se tais posicionamentos.

As análises e a articulação esboçada no presente texto pretenderam mostrar como a subjetividade e a intencionalidade estão em cena no trabalho jornalístico. As paixões, os afetos, as emoções e, consequentemente, o próprio fazer enunciativo encontram-se materializados e referencializados nas configurações verbais e icono-visuais também de veículos de comunicação tidos como informativos. Porém, sempre há espaço para tensionamentos que podem ser instaurados com uma análise mais apurada a partir de conceitos da própria semiótica. As noções de tensividade, energia, intensidade, extensão e quantidade trabalhadas por Jacques Fontanille e Claude Zilberberg, os conceitos de experimentar, de experiência sensível, de contágio e semiótica da união de Eric Landowski ou, ainda, a articulação entre semiótica das paixões e psicanálise proposta por Waldir Beividas (Fontanille, 2019) podem ajudar a explicar e compreender o jornalismo na intrínseca conexão com o sensível.

Submetido em 1 de agosto de 2020 Aceito em 25 de maio de 2021 


\section{REFERÊNCIAS}

Aguiar, Tarcísia. (2012). "O contínuo genérico presente na capa de jornal”, Investigações, 25(2), p. 133-155.

Barros, Diana. (2004). "Publicidade e Figurativização”, Alfa, 48(2), p. 11-31.

Barthes, Roland. (2008) Del deporte y los hombres. Barcelona: Paidós.

Bento, Jorge. (2013). "Futebol: sonhos, paixões e cultura", Revista USP, 99, p. 11-30.

Buonanno, Milly. (2015). “Al fronte, ma non sulla front page: Giornaliste in prima pagina", Problemi dell'informazione, 40(3), p. 483-502.

Caillois, Roger. (1990). Os jogos e os homens: a máscara e a vertigem. Lisboa: Cotovia.

Campos, Anderson. (2014) A economia das imagens do esporte: Produção, reprodução e valoração de bens imagéticos nos ambientes midiáticos dos megaeventos esportivos. [Tese de Doutorado, Pontifícia Universidade Católica de São Paulo].

Carvalho, Flaviane. (2012). Semiótica social e imprensa: o layout da primeira página de

jornais portugueses sob o enfoque analítico da gramática visual. [Tese de Doutorado, Universidade de Lisboa].

Casagrande, Magnos. (2019). Futebol, jogo e paixão: A Copa do Mundo de 2014 em capas de jornais. [Tese de Doutorado, Universidade Federal de Santa Maria].

Castro, Maria. (2012). "A fala autorreferencial na televisão brasileira: estratégias e formatos”, Comunicación, 1(10), p. 78-93.

Charaudeau, Patrick. (2006). Discurso das mídias. São Paulo: Contexto.

Costa, Leda. (2010). "Um teatro de sensações. Imprensa esportiva, melodrama e folhetim”, Ciberlegenda, 22, p. 92-110.

Fiorin, José. (2007). "Paixões, afetos, emoções e sentimentos", Cadernos de Semiótica Aplicada, 5(2), p. 1-15.

Fontanille, Jacques. (2019). "As vias (e as vozes) do afeto", Galáxia, 2, p. 137-162.

Fortes, Rafael. (2015). O mundial de 2014 no imaginário popular brasileiro. In: MARQUES, J. C. (Org.). A copa das copas? Reflexões sobre o mundial de futebol de 2014 no Brasil (pp. 39-56). São Paulo: Ludens.

Gadret, Débora. (2018). A emoção e a organização do enquadramento no jornalismo. In: Pichiguelli, I; Carlos Silva,
M. C.; Martinez, M.; Santos, T. C.; Heidemann, V. (Orgs.). Afetos em narrativas (v.1, pp. 290-315) Alumínio, SP: Jogo de Palavras.

Gebauer, Gunter \& Wulf, Christoph. (2004). Mimese na cultura: agir social, rituais e jogos, produções estéticas. São Paulo: Annablume.

Greimas, Algirdas \& Fontanille, Jacques. (1993). Semiótica das Paixões. São Paulo: Ática.

Greimas, Algirdas \& Courtés, Joseph. (2012). Dicionário de Semiótica. São Paulo: Contexto.

Hartmann, Camila. Fanfa, Maurício \& Silveira, Ada. (2020). "Reconfiguração editorial: ainda há capas em jornalismo de plataforma?”, Sur le journalisme, 9(1), p. 104-117.

Huizinga, Johan. (2020). Homo-Ludens. São Paulo: Perspectiva.

Lovisolo, Hugo. (2011). "Jornalismo e esporte: linguagem e emoções", Corpus et Scientia. 7(2), p. 91-99.

Medina, Cremilda. (2008). Ciência e jornalismo: da herança positivista ao diálogo dos afetos. São Paulo: Summus.

Motta, Luiz. (2003). "O jogo entre intencionalidades e reconhecimentos: pragmática jornalística e construção dos sentidos”, Comunicação e Espaço Público, 6(2), p. 7-38.

Mozdzenski, Leonardo. (2018). O pathos como estratégia de discursivização e narrativização das afetividades. In: Pichiguelli, I; Carlos Silva, M. C.; Martinez, M.; Santos, T. C.; Heidemann, V. (Orgs.). Afetos em narrativas (v.1, pp. 118142) Alumínio, SP: Jogo de Palavras.

Peruzzolo, Adair (2015). Elementos de Semiótica da Comunicação (3.ed.). Jundiaí, SP: Paco Editorial.

Ryan, William \& Conover, Theodore. (2004). Graphic Communication Today (4. ed.). New York: Thomson Delmar Learning.

Sodré, Muniz (2006). As estratégias sensiveis: afeto, mídia e política. Rio de Janeiro: Vozes.

Valdetarro, Sandra. (2003). "La 'puerta de entrada' a Página 12: propuesta para um análisis del contrato de tapa", La trama de la Comunicación, 8, p. 15-20.

Volli, Ugo. (2010). "Por uma definição semiótica do esporte", Dobras, 4(9), p. 116-119

Wahl-Jorgensen, Karin. (2012). "Subjectivity and story-telling in journalism”, Journalism Studies, 14(3), p. 305-320. 


\section{RESUMo | ABSTRACT | RÉSUMÉ}

Investimento de aspectos passionais no discurso da imprensa esportiva: promoção de intencionalidades e posicionamentos editoriais

Le recours au passionnel dans le discours de la presse sportive : mise en lumière des intentionnalités et du positionnement éditorial

\section{Passion in the discourse of sports press: promoting intentionality and editorial} positioning

Pt.

O estudo parte do princípio de que é pela via de aspectos passionais que a discursivização da eliminação da Seleção brasileira na Copa do Mundo de Futebol de 2014 configura o modus operandi das instâncias jornalísticas. Sustenta-se que o futebol é enunciado e anunciado pelo jornalismo esportivo com forte presença do argumento da paixão, pois esta é intrínseca ao fazer discursivo jornalístico. Diante disso, propõe-se responder que marcas discursivas passionais e que posicionamentos editoriais são manifestados na cobertura jornalística da eliminação da Seleção brasileira na Copa do Mundo de Futebol de 2014 e que relações é possível traçar com as eliminações ocorridas na edição anterior (2010) e na edição posterior (2018). Objetiva-se mapear o investimento temático-figurativo constituinte das capas de jornais impressos e propor explicações sobre a relação que se estabelece entre capas, aspectos passionais, intencionalidades e posicionamentos editoriais. Como objeto empírico, seleciona-se capas de jornais impressos brasileiros. Considera-se que a capa de jornal avança sobre características canônicas do jornalismo tradicional e se apresenta como um elemento estratégico, identitário e promocional. Analisa-se um total de 45 exemplares. Para as análises, recorre-se ao aporte metodológico da semiótica discursiva greimasiana, utilizando-se de preceitos relativos às paixões e ao percurso gerativo de sentido. Explorando o nível discursivo, analisa-se o investimento temático-figurativo constituinte das capas. Enquanto a tematização se refere a ideias, valores, pensamentos e argumentos num plano abstrato, a figurativização estabelece a conexão entre estes e o mundo natural. Os resultados apontam para a capa como um dispositivo que atua na promoção de intencionalidades das instâncias jornalísticas. A mobilização de cenários passionais torna-se um caminho encontrado para legitimação de posicionamentos editoriais. Constantemente, exploram-se paixões dicotômicas, como aquelas de alegria e de tristeza, de proximidade e de afastamento. Constata-se a reiteração de um senso de urgência na busca pela interpretação e compreensão dos acontecimentos, que conduz a mudança repentina de posicionamento a ser apresentada de maneira natural. Por fim, os resultados indicam a necessidade de reconhecimento do potencial do sensível e dos afetos para emancipação das relações de comunicação.

Palavras-chave: Discurso. Futebol. Paixão. Jornalismo. Promocionalidade.

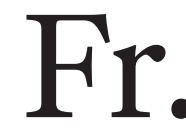

Cette étude part du postulat que c'est à travers des aspects passionnels que la mise en discours médiatique de l'élimination de l'équipe nationale brésilienne à la Coupe du monde 2014 s'est opérée. Nous allons démontrer que le football est énoncé et annoncé par le journalisme sportif avec une forte présence du registre passionnel, qui est lui-même intrinsèque à cette mise en récit journalistique. Compte tenu de cela, nous proposons de montrer quelles marques discursives passionnelles et quelles positions éditoriales se manifestent dans la couverture médiatique de l'élimination de l'équipe nationale brésilienne à la Coupe du monde 2014 et quelles relations peuvent être établies avec les éliminations qui ont eu lieu lors de l'édition précédente (2010) et de l'édition suivante (2018). Cette recherche vise à cartographier l'investissement thématique-figuratif constituant les couvertures des journaux imprimés et à proposer des explications sur la relation qui s'établit entre les unes, les aspects passionnels, les intentionnalités et les positions éditoriales. Notre corpus est constitué des unes de journaux imprimés brésiliens. On considère que la Une en tant qu'objet d'étude contient les caractéristiques canoniques du journalisme traditionnel et se présente également comme un élément stratégique, identitaire et pro- 
motionnel. Au total, 45 exemplaires ont été analysés, en ayant recours à l'apport méthodologique de la sémiotique discursive greimassienne. Nous avons utilisé des préceptes relatifs au registre passionnel et au parcours génératif du sens. Au niveau discursif, l'investissement thématique-figuratif des couvertures est analysé. Alors que la thématisation fait référence à des idées, des valeurs, des pensées et des arguments à un niveau abstrait, la figurativisation établit le lien entre ceux-ci et le monde naturel. Les résultats indiquent que la Une est un dispositif qui agit dans la promotion des intentionnalités des instances journalistiques. La mobilisation de scénarios passionnels devient alors un moyen pour légitimer les positions éditoriales, à travers le recours à des passions dichotomiques, comme celles de la joie et de la tristesse, de la proximité et de l'éloignement. Cela se traduit également par la réitération d'un sentiment d'urgence dans la recherche de l'interprétation et de la compréhension des événements, ce qui conduit à présenter de façon naturelle le changement soudain de position. Enfin, les résultats indiquent la nécessité de reconnaître le potentiel du sensible et de l'affectif pour l'émancipation des relations de communication.

Mots clés : Discours ; football ; passion ; journalisme ; promotion

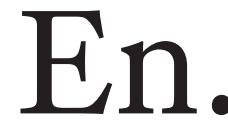

This study is based on the proposition that the media discourse on the disqualification of the Brazilian national team during the 2014 World Cup is We demonstrate that football is stated and announced by sports journalism with a strong presence of the register of passion, which is in itself a defining quality of the journalistic storytelling. Based on this observation, the many shapes taken on by passion, from discursive marks to editorial positions, are examined in the media coverage of the disqualification of the Brazilian soccer team during the 2014 World Cup, and compared with the previous and following World Cup editions (2010 and 2018). This research aims at mapping the thematic-figurative investment present in cover pages of printed newspapers. It suggests that there is a relationships between cover pages, passion, intentionality and editorial positions. The corpus is composed of cover pages of Brazilian printed newspapers. As an object of study, cover pages are considered to represent the canonical characteristics of traditional journalism while also playing a role in commercial strategy, branding and promotion of the newspaper. A total of 45 cover pages were analyzed, based on the discursive semiotics methodology developed by Greimas. Our analysis is supported by precepts related to the register of passion and the generative trajectory of meaning in discourses. At the discursive level, the thematic and figurative investment of the cover pages are analyzed. While thematization refers to ideas, values, thoughts and arguments at an abstract level, figurativization links these to the natural world. Results demonstrate that covers page constitute devices acting as an amplifier of the intentions of journalistic institutions. Resorting to passionate scenarios then becomes a means to legitimize editorial positions. Opposing passions, such as joy and sadness, proximity and distance, are constantly explored. A sense of urgency is recurrent and underlies the interpretation of events, allowing to present the sudden changes in the editorial position as natural. Finally, results suggest the need to take into account the potentiality offered by the register of emotions and sensitivity to emancipate communication relations.

Keywords: discourse; soccer; passion; journalism; marketing. 